This text is based on the study performed about the engraving creation process of $\mathbf{D}$ (irso) $\mathbf{J}$ (osé) de Oliveira. It doesn't worry about dealing with his work as a finalized product, but with his action manners to produce the artistic object. Among the variety creation procedures developed by the artist, it is intended to give emphasis to some imaginative mechanisms which were planned by him to produce the engraving. By the time we chose to approach the artist's action manners but neither the subject nor the finalized work, it makes clear that the look was focused, during the research, on the path to create the engraving. It is understood the action of creation as a communicative action, as considering the creative action as semiotics, an action that moves in several directions and includes cultural aspects, material, accumulated memory, and subjectivity. While producing the work, the artist gathers and filters the social cultural environment matter. When he follows his steps, when he guides himself through his drawings to produce his works, he communicates himself in an intrapersonal way.

Keywords: process, engraving, creation. 


\section{DJ Oliveira e a gravura em Goiás}

\section{Edna de Jesus}

GOYA

Este texto tem como base o estudo realizado sobre o processo de criação de gravura de D(irso) J(osé) de Oliveira. Preocupa-se em abordar não a sua obra, enquanto produto finalizado, mas os seus modos de ação para produzir o objeto artístico. Dentre diversos procedimentos de criação desenvolvidos pelo artista quer-se destacar alguns mecanismos imaginativos que foram arquitetados por ele para produzir a gravura. Ao se optar por abordar os modos de ação do artista e não o sujeito ou a obra, finalizada, esclarece-se que o olhar esteve focado, ao longo da pesquisa, no se percurso para criar a gravura. Entende-se o gesto de criar como uma ação comunicativa, ao considerar a ação criadora como semiose, um gesto que se movimenta em várias direções e envolve aspectos culturais, material, memória acumulada e subjetividade. O artista ao produzir a obra colhe e filtra a matéria do ambiente sociocultural. Ao segui seus passos, ao orientar-se pelos seus desenhos para produzir comunica-se de modo de modo intrapessoal.

Palavras-chave: processos, gravura, criação. 
A base para esse texto é o estudo de documentos de processo, base para se investigar o percurso da criao, uma das formas de se ter acesso à obra (resultado). Objeto de investigação da Crítica Genética de base semiótica, o estudo de documentos centra-se nas ações de construção, e entende o gesto criador como uma ação comunicativa, assunto sobre o qual falaremos mais à frente. O estudo de documento tem sido uma das preocupações da arte contemporânea, pois, nesta tendência, às ações do artista nem sempre resultam em obras ou objetos concretos, mas em conjecturas. Entende-se que a investigação da intimidade da criação, na arte e na ciência e, em qualquer linguagem, poderá contribuir para a compreensão da obra.

Para falarmos da obra pelo processo é importante que se aborde o artista. Esse procedimento tem função de localizá-lo, não como sujeito psicológico, que produz ações, mas para se compreender os gestos de um sujeito que é criador e produz, impregnado do meio em que vive. É um sujeito incrustado no seu mundo, vive integrado nele, se torna parte dele. Esses fatores contribuem e interferem no modo de construção. Pelo estudo de processo, pela investigação do modo de ação de DJ Oliveira, pode-se destacar aspectos que faz a sua obra se tornar singular no contexto da criação e da gravura, e evidenciar a sua importância para a arte de Goiânia, bem como as suas contribuições para o desenvolvimento e sedimentação da arte e da cultura local ou para a arte mais amplamente. Pode-se descobrir como se dá a construção de sua subjetividade artística.

Como procedimento, inicial, para se investigar o processo de criação do artista começamos por levantar o maior número, possível, de documentos, respectivos à elaboração de sua obra, para posterior organização, catalogação e leitura. Em DJ Oliveira os documentos de criação são os desenhos.

Após a classificação dos fizemos a identificação dos temas explorados por ele, e procuramos descobrir a aplicabilidade dos mesmos; se para a pintura, mural ou gravura. Identificamos os métodos e técnicas de produção de gravura, e as recorrncias de ações no processo. Elas foram nomeadas, e deram origem a uma listagem de categorias de produção, denominados pro- 
cedimentos criativos, mecanismos imaginativos, produzidos e aplicados pelo artista para fazer a obra.

O passo seguinte, no processo leitura da criação, refere-se à análise, ao estabelecimento de conexões entre as informações das diferentes categorias de procedimentos. Significa que se devem ler as ações de modo não linear, e sim, gestos que ocorrem em várias direções. Neste procedimento se deve desvelar, desdobrar, esmiuçar, expandir e conectar as ações do artista que estão escondidas por traz da obra, sem perder de vista o contexto em que o objeto está sendo construído. A discussão deve ser ampliada para além da origem da linguagem produzida pelo artista, ou de seu currículo, para identificar as informações, decifrá-las e articulá-las à rede que forma o movimento da criação, pois os gestos criadores estão interligados.

Para não se ler os gestos do artista como fatos isolados do contexto sociocultural se buscou identificar, nos documentos e obras, traço (signos) da cultura que denunciassem formas de diálogos de DJ Oliveira com o ambiente vivencial. A necessidade de se falar de seu modo de inserção no lugar deu-se por se considerar que o fazer humano, seja ele científico ou artístico, carrega para os produtos marcas do olhar do sujeito. Compreende-se que suas ações são pautadas pela cultura.

Ler a obra pelos modos de ao implica, portanto, em se ampliar o debate sobre as ações de DJ Oliveira para além de se listar o seu currículo, ou de falar de sua vinda para Goiás, ou de inserir o seu nome na lista dos artistas fundadores da gravura goiana. Requer falar de suas escolhas e procedimentos. Para reconstruir os passos do artista e desvendar a sua intimidade para fazer a obra (gravura) buscamos compreender as mincias de seus modos de ação. Por ser o artista pintor, muralista e gravador, a investigação foi realizada sobre 536 documentos, pois muitos desenhos são materializados, em obras, nas três áreas de atuação de DJ Oliveira.

Mas é claro que não seria viável uma abordagem tão complexa sobre a criação da gravura do artista em tão curto espaço e tempo e, por esta razão, se acha importante recortar apenas algumas questões que envolvem e marcam o processo de criação do artista, a começar por situar DJ Oliveira, quanto 
a sua origem e formação. No decorrer do texto, faremos a conceituação de gravura e criação e falaremos da forma de inserção do artista no lugar. Destacaremos o papel do desenho e alguns procedimentos, ou mecanismos imaginativos, plásticos, criados e aplicados pelo artista, para a produção de sua obra. O propósito da investigação é descobrir que caminho é este e que aspectos do processo criativo marcam a sua singularidade.

\section{DJ Oliveira: origem e formação}

DJ Oliveira nasceu em Bragança Paulista, em 14 de novembro de 1932 e faleceu em 23 de setembro de 2005, em Goiânia, GO. Começou a interessar-se pelas Artes Visuais aos nove anos. Seu contato com a arte foi através da reprodução de histórias em quadrinho.

Em 1942, fez suas primeiras experiências, em sua cidade, em pintura à têmpera e se tornou ajudante de Caetano Corrêa, cartazista de cinema, pintor e decorador. Com o artista, conheceu a pintura em mural e se interessou pela linguagem, dada a possibilidade de explorar grandes espaços.

Em 1943, DJ Oliveira começou a trabalhar com pintura a óleo, em estilo natural, com Luís Gualberto, pintor paisagista de sua cidade. Gualberto o indicou para o Liceu de Artes e Ofícios, para continuar seus estudos, mas DJ Oliveira não conseguiu a vaga para o curso artístico, por falta de estudos anteriores. Registre-se que Gualberto fora orientado por Colette Pujol, professor de Pintura do Liceu de Artes e Ofícios, atual Pinacoteca do Estado.

Em 1946, DJ Oliveira mudou-se para São Paulo, capital, e começou a trabalhar com Florêncio Caruzo, pintor e artesão especializado em decoração de paredes, realizando pinturas, frisos, bocas de cena, painéis e murais.

Em 1954, conheceu Luciano Maurício, cenógrafo do Ballet do IV Centenário, com quem aprendeu conceitos de cenografia e o introduziu na arte moderna e nos estúdios da TV Tupi, onde trabalhou por alguns anos. 
Fez sua primeira exposição como pintor paisagista em 1955, com a participação em uma coletiva no Clube dos Artistas Modernos, de São Paulo. O grupo, conforme DJ Oliveira (2005), era de tendência acadêmica.

Na capital paulista, conviveu com vários grupos ${ }^{1}$ de artistas, como o da Fundação Álvares Penteado, e o Grupo de Laurindo Galante, escultor e professor do Liceu, e da Escola Técnica Getúlio Vargas, grupo que atuava nos finais de semana. Com Galante, teve noções de Desenho, em 1948 e 1949. Os artistas desse grupo, conforme DJ Oliveira (2005), eram mais liberais. Conhecidos como o Grupo do Braz, dele faziam parte Galante, Saint Bullo, Francisco de Fiori, pintor e desenhista, Ângelo Desordi e Salvador Rodrigues. Os artistas desses grupos eram, na maioria de descendência italiana, e orientados por Collette Pujol.

Eles reuniam-se à noite na sala de estudo, na Rua Quintino Bocaiúva (SP), para desenhar, orientados por Galante. Nesse grupo, DJ Oliveira conhece Francisco Priori, que o apresentou a Volpi, e este o apresenta ao Grupo Santa Helena (O GHS, em 1949).

Com o Grupo do Braz, liderado por Priori, e com o Grupo Santa Helena, DJ Oliveira expandiu as atividades artísticas artesanais para a pintura.

Por necessidade de trabalho, DJ Oliveira resolveu mudar de São Paulo, em busca de novas oportunidades. Em 1955 deixou o Grupo Santa Helena e transferiu-se para Goiás, em 1956, distanciando-se da Associação Paulista de Belas Artes.

No novo Estado, retomou seu trabalho artístico ligado aos aspectos artesanais - cartaz, decoração de paredes e letreiros. Posteriormente, estabeleceu laços com a arte dramática, por meio da cenografia.

Em Goiânia, foi apresentado, por Batista Custódio, ao diretor do Teatro de Emergência, João Bennio, e entre 1958 e 1959 realizou seu primeiro cenário na cidade, para Vestido de noiva, de Nelson Rodrigues. Quando Bennio inaugurou seu teatro, DJ Oliveira produziu o cenário da peça $A$ raposa e as uvas, de Guilherme Figueiredo, entre 1959 e 1960. A cenografia era o campo mais aproximado das artes plásticas, meta do artista. 
Por meio do cartaz e da cenografia, DJ Oliveira tornou-se reconhecido na cidade. Luiz Curado, diretor da Escola Goiana de Belas $\operatorname{Artes}^{2}$ (EGBA), que assiste à peça, raposa e s uvas, sente-se impressionado com a experiência do artista em cenografia, o convidou para fazer parte da escola. Por achar que não tinha tendência para o ensino, DJ Oliveira recusou o convite, e a ligação com a escola só aconteceu posteriormente.

Ao retomar o trabalho artístico iniciado em São Paulo, tornou-se fundador do primeiro Ateliê Livre e Coletivo ${ }^{3}$ de Pintura Moderna do Estado. Nesse ateliê os artistas atuavam de forma anônima, aos sábados e domingos. Em 1959, DJ Oliveira fundou o seu próprio ateliê, denominado Mona Lisa, na Avenida Anhangüera, em Goiânia, nos fundos do Teatro de Emergência. Essa experiência de criar os ateliês coletivos resultou do convívio com os grupos de artistas de São Paulo.

O fato de começar a pintar pelas ruas da cidade e se considerar um artista livre, por não pertencer aos grupos de artistas da cidade, o conduziu, pela ousadia e irreverência, à incompreensão, chegando a ser tratado como aventureiro e inconseqüente. A discriminação ocorria também, conforme DJ Oliveira (1996), por desafiar dogmas artísticos estabelecidos na cidade. Isto porque, em Goiás, na época, pintar pelas ruas era acontecimento incomum. A capital acabara de ser transferida e, embora fosse jovem e aberta às inovações e em pleno desenvolvimento, a sociedade tinha hábitos conservadores, ligados ao campo.

A partir das experiências na cidade, em cenografia e decoração, reiniciou a sua carreira artística, como pintor, mas sem muitas pretensões. Preocupou-se com a pintura de paisagens, especialmente da periferia da cidade. A fase inicial do artista, de característica naturalista, marcou o início da carreira de DJ Oliveira (no período de 1955 a 1960).

Se antes buscava, por meio da pintura e do desenho, a perfeição das formas - a representação da natureza, com naturalismo, expressas no apuro técnico e na manipulação harmoniosa de cores e materiais - depois, a preocupação de DJ Oliveira era definir sua tendência como pintor moderno.

Sair de um grande centro de produção e mudar-se para Goiás naquela época era inicialmente uma aventura. A deci- 
são de mudar-se para uma cidade menor resultou em desafios que iriam marcar a vida do artista. A mudança leva o artista a modificar não só os rumos de sua vida pessoal, mas a assumir definitivamente a carreira de artista plástico, com opção pela pintura de cavalete e mural e, depois, pelo ensino de artes, na EGBA.

Por ser um artista considerado moderno e arrojado, foi novamente convidado, em 1961, por Luiz Curado a integrar o grupo de professores da EGBA. Na escola, ensinou desenho, pintura, gravura em madeira e, depois, em metal. Posteriormente, em 1964, fundou juntamente com outros artistas, o primeiro Ateliê livre dessa escola, além de continuar atuante como artista, com inúmeras participações em salões de arte.

\section{O que é gravura}

Pela necessidade de se localizar os meios de produção da linguagem impressa, cujos documentos de criação fundamentam o estudo, remete-nos, necessariamente, a definir o que é gravura e a listar os método e técnicas de impressão, praticados por DJ Oliveira que são a xilografia ${ }^{4}$ (ao fio) e calcografia ${ }^{5}$, em ferro, nas técnicas de água-forte, água-tinta, água-tinta de açúcar e ponta-seca.

O termo gravura deve ser aqui entendido como o processo de transformação da superfície plana de um material, seja ele duro, mole ou flexível, num mediador de imagem. É criação pela matriz - prancha, fôrma, chapa ou carimbo - para reproduzir um certo número de vezes, uma imagem desejada, pela transferência, dessa, por fricção ou prensagem, para um suporte (papel), por intermédio da tinta, elemento visualizador da imagem.

A xilografia é a gravura em relevo, feita, geralmente, em madeira e em outros materiais como gesso ou borracha. Nesse método de gravação, a madeira é cortada por meio de goivas, ferramentas de corte, com diversidade de formatos na ponta. A calcografia é a gravura realizada em chapas de metal, também denominada gravura talho-doce, em oco, côncavo, curva ou entalhe. Nesse modo de gravação a matriz é 
gravada por meio de ferramentas cortantes ou por meio da corrosão de ácidos.

A obra impressa, a gravura artística ou estampa, foco de nossa abordagem, resulta de um meio indireto de produção de imagem, e envolve ações complexas, em diversos níveis de etapas, materiais, métodos e técnicas de impressão. A estampa, a obra, decorre de matriz (fôrma) e de desenho. Envolve, corte (entalhe) e/ou ação e reação de ácidos para a gravação da mesma, bem como diferentes modos de impressão de cópias. Existe peculiaridade no modo de assinatura, geralmente a lápis, fazendo com que a arte impressa se diferencie das demais linguagens, que resultam da ação direta do artista sobre o material, a exemplo da escultura, da pintura e do mural. Às diversas ações criadoras praticadas pelo artista e, como dito, se denomina procedimentos.

$\mathrm{Na}$ gravura, o desenho pode ser realizado previamente ou não sobre uma base (papel). É transportado para a matriz ou realizado diretamente sobre a mesma. Esta é escavada (gravada) e entintada. A imagem, cortada na matriz, é entintada e transportada para o papel pela pressão.

A produção de imagem por entalhe e impressão exige diversos procedimentos e ações, técnicas, e complexidade de movimentos por parte do artista, seja o resultado da criação gravura de arte ou não.

\section{Aspectos do processo de criação, a inserção do artista} na cultura e traços da construção da subjetividade

O modo como cada artista estrutura o espaço de trabalho - o ateliê, ou escolhe os livros que vão para a estante pode nos dar pistas sobre sua forma de pensar, mas é, especialmente, o modo de olhar, selecionar, se apropriar e levar para a obra a matria que vem denunciar o seu modo particular de criar.

Pela maneira como se organiza e se relaciona com o espaço de trabalho - organiza o ateliê ou pelos livros que lê, pode nos dar pistas de sua maneira de pensar, mas a particularidade se constitui pelo modo como a percepo age para selecionar a 
matéria a ser levada para a obra. É pelo modo como retira e faz uso dos materiais, do ambiente e da cultura, para construir a obra que mostra a sua particularidade. É no modo de fazer a obra que pode ser localizada a caligrafia artística. Assim, são os modos, procedimentos, e atitudes que o levam à construção da marca que define o seu estilo.

Ainda que diferentes artistas tenham acesso aos mesmos materiais, técnicas, ou convivam num mesmo espaço e cultura, olhem para os mesmos objetos, ainda assim, suas obras serão sempre diferentes, fazendo com que cada um seja único. Isto porque cada indivíduo olha o mundo de um modo diferente. Assim, a obra será resultado da pesquisa, da experiência, da memória acumulada, procedimentos técnicos e materiais, mas a diferença consiste, especialmente, no modo de apropriação da matéria para construí-la. Assim, a individualidade da obra caberá à percepção, pois é através dela que o artista colhe as informações e pelo conhecimento as transforma em obra.

Os documentos de criação podem mostrar os entrelaçamentos que acontecem no processo, bem como os diferentes tempos e simultaneidade em que se dão os movimentos do fazer artístico. Mas também podem tornar evidente a histria produtiva do artista ao se tentar ler o objeto pelos modos de elaboração.

O que queremos, na verdade, dizer é que o termo "processo de criação" se refere à narrativa para falar do acontecimento "criação", vivenciado pelo artista: das metas e dos percursos feitos por ele para realizar a obra. Pois, são as metas - a causação final (os motivos), que dão sentido às suas ações: de desenhar e gravar. O desejo de realizar a obra o impulsiona a novas ações. Isto - desejo para criar -, envolve atitude física, intelectual e emocional, se transforma em práxis.

Nesta perspectiva, estaremos afirmando que o processo de criação, enquanto ação que se movimenta com tendência vaga, em busca da linguagem, deve ser visto como trabalho, fruto de um aprendizado, decorrente de experincias internas e externas: do convívio com as pessoas, com o mundo, com a cultura. Isto significa que a obra resulta de convicções, princí- 
pios, experimentos: erros, acertos, do conhecimento, da experiência e do sensível: de emoções.

A proposta de se falar um pouco sobre as relações de construção que estão por traz da obra do artista, faz-se no sentido de se entender, pelos documentos de processo, como acontece o planejamento e elaboração da obra.

Para falar da arquitetura construtiva desenvolvida pelo artista para produzir a gravura é necessário falar da função do desenho, materiais e processos de impressão adotados pelo artista, bem como das implicações da mudança dele, de um luar para outro, pois toda e qualquer ação/movimento do artista pode interferir no processo de criação.

A necessidade da investigação processual se faz ao entender que, embora, o artista siga sua tendência rumo à materialização da linguagem da gravura (da obra) o percurso é incerto e interligado a outros acontecimentos e situações, diretos e indiretos. Desse modo, investigar o processo de fabricao da obra, dá-se para se saber que procedimentos, mecanismos e possíveis leis internas regem a criação e como são aplicadas à obra e as implicações do lugar cultural na obra.

A preocupação de se conhecer os diálogos entre sujeito e cultura dá-se com o intuito de conhecer formas de apropriação dos signos do ambiente para se saber como faz uso da matéria. Isto, porque acreditamos que o conhecimento dos passos do artista rumo a construção do objeto contribui para a compreensão da obra. Pois, ainda que o artista tenha em mente o desejo de fazê-la, o percurso, dada a complexidade e entrelaçamentos, nem sempre é objetivo. "O trabalho caminha para um maior discernimento daquilo que se quer elaborar. A tendência não apresenta já em si a solução concreta para o problema, mas indica o rumo. O processo é a explicação dessa tendência. (SALLES, 1998, 29)".

Em outros estudos de casos, em que se analisam minúcias processuais, realizados pelo Centro de Estudos de Crítica Genética (CECG/PUC/SP), a preocupação tem sido no sentido de conhecer pela análise do material; dos vestígios deixados pelo artista, para construir a obra, os pensamentos (teóricos e práticos) que sustentam o processo produtivo dele. 
O trabalho do crítico genético é investigar pistas deixadas pelo artista a partir do material (documentos), enquanto que o crítico de processo acompanha o trabalho do artista no seu local de produção. O crítico genético tem com referência para a análise da obra os documentos de processo para ler os modos de ação dele. Deve-se analisá-los, mas levando em conta o contexto em que foram produzidos, para descobrir os novos significados que foram dados pelo artista.

O modo como cada artista olha para o ambiente e para a cultura seleciona, faz uso da matéria para elaborar a obra, pode nos mostrar como o seu olhar funciona. Focillon, em $\mathrm{O}$ mundo das formas (p. 73), diz que "as técnicas não são a técnica. Uma coisa é o conjunto das regras de um ofício. Outra é a maneira pela qual estas, fazem viver as formas na matéria".

A maneira como cada material, do ambiente e da cultura, é apropriado (tomado) pelo artista torna-se uma ferramenta, mas, ao mesmo tempo, um dado a ser desvendado no processo do artista. O valor que é lhe é atribuído, assim como o significado do objeto dentro do contexto da criação é um dado a ser observado. Posto, buscamos olhar o objeto artístico sob o viés da crítica genética que tem como método de estudo os documentos de criação do artista e não a obra.

Mas, na análise processual não basta conhecer a obra ou olhar os signos presentes nos documentos com a intenção de identificá-lo, mas estabelecer relação, entre eles, no projeto de obra, deles, como conjunto dos documentos, e dos documentos com a obra. Tampouco importa descrever o processo criador ou falar do artista ou da obra, mas tentar reconstruir os passos do artista com o intuito de descobrir o pensamento que está por traz da construção da imagem impressa: da gravura enquanto obra.

Para se expressar e comunicar, pela arte, o artista faz apropriações e transformações da realidade. Pelos modos de construção plástica podemos compreender como lida com a matéria para construir. Isto significa que devemos olhar para os documentos de processo de criação para entender, pelas relações de fabricação: pelas relações que o artista estabelece entre os elementos colhidos, no ambiente e na cultura, que formas de 
diálogo estabelece com eles para fazer a obra. A proposta é discutir os documentos de processo da gravura de DJ Oliveira, a partir de sua mudança, de São Paulo, e inserção, em Goiás. A partir do contexto.

O artista se muda de um lugar para outro, ficando em princípio sem lugar, desprovido de parte de sua história pessoal. Perde o convívio com artistas de seu lugar de origem. Mas, ao contrário de se deixar levar pelas imposições do contexto busca maneira própria de inserir-se nele: pelo plástico. Apropria-se das narrativas do lugar (das historias ou causos) como pretexto para a criação e para inserir-se no lugar.

Pelos modos de ação, pelo gesto ou ação: de desenhar e gravar tornar-se-á possível mostrar como isto acontece no processo de criação dele. Pela maneira como lida com os objetos colhidos e são levados para os documentos podemos verificar como os diálogos se estabelecem, ou seja, nos torna possível conectá-los a rede de relações que envolvem a criação e descobrir os diferentes entrelaçamentos, em que se dá a produção criadora.

O processo de criação acontece em diferentes momentos, níveis e etapas, e os documentos se materializam como uma das etapas e como inteno de obra. Todavia, é por meio dos materiais e das técnicas de gravura que os propósitos se transformam em obra. O objeto, pronto, torna-se, neste sentido, o vencimento de uma etapa dentro do processo do artista e referência para a análise da criação. Na verdade, buscamos entender a dimensão do desenho enquanto forma de representação, gráfica intermediária às construções plásticas, mas sem perder de vista os materiais, métodos e técnicas de gravura, e o contexto em que foram produzidos.

A preocupação é compreender a significação de cada gesto do artista: de desenhar e gravar no processo. As ações para produzir a obra, por sua vez, não devem ser lidas isoladamente, mas vistas como fazer de um sujeito que está conectado à cultura e ao meio. Apropria-se dos elementos do contexto das narrativas (das historiar ou dos causos), e as mostra, pela obra, transformadas, como ponto de sustentação criadora. Os objetos, do ambiente e da cultura, são colhidos e redimensio- 
nados, pela percepção, e levados para os documentos de processo e para a obra.

Com o intuito de localizar a discussão tomamos como objeto os documentos de processo de criação de gravura de Oliveira, artista que deixa São Paulo e se muda para Goiás, em 1956. Sua carreira artística tem início no começo dos anos sessenta, década de conflitos políticos, causados pela repressão e pelas mudanças conceituais na arte brasileira. DJ Oliveira pratica uma arte "dentro" dos ateliês e na especificidade das linguagens: da pintura, do painel em cerâmica e afresco e gravura.

$\mathrm{Na}$ década de 1060, novas preocupações começam a fazer parte do cenário artístico, com respeito à atualização das linguagens. Neste cenário a arte começa não só a estabelecer novos diálogos com outras formas de arte como desencadeiam novas formas de manifestações, com redimensionamento no uso dos materiais e técnicas.

A arte desse período vem tirar a obra do "quadro", do "pedestal" ou da "parede" como objeto para ser "emoldurado", feito para ser "contemplado" e se volta para um objeto que pode ser "tocado" e experimentado, feito em espaços outros, "fora" do ateliê. Tende para o abstracionismo informal e o concretismo, abrindo espaço para uma nova forma de organização realista do mundo.

O impulso dessa fase da arte, no Brasil, centra-se numa posição crítica frente à realidade social e política em que vivia o país, marcado pelo regime de Ditadura Militar, pelos conflitos sociais, que, associados à economia, a instalação do Al-5, em 1969, propiciaram as mobilizações pós 64 e favorecem as transformações do momento.

A arte desse período caracteriza-se, conforme Vernaschi. (1997, p. 23) por "uma diluição dos limites de aspectos formais, estéticos e técnicos através do uso de novos materiais, industriais, inclusive. O advento do happening e a arte conceitual - ênfase na arte enquanto idéia - desmaterializam a arte".

E é neste cenário, de mudanças na arte, que a gravura, centrada no material e na matriz como base para produzir a imagem e reproduzir a obra passa não só quebrar os hábitos da tradição - da "cozinha" ${ }^{6}$ da gravura, sustentada no rigor técni- 
co, mas, experimentar. Os gravadores começam adotar novos modos de usar os materiais e recursos técnicos para a obtenção da estampa, como a exemplo, o xerox (processo fotomecânico). Tais alterações conceituais tiveram como finalidade não somente produzir uma obra, mas dar à idéia artística uma nova morfologia de invenção.

Mas, por outro lado, outros artistas, desta mesma época, mantêm-se fieis aos princípios "modernos", manifestando um outro tipo de preocupação, mas não com a com a abstração em si, ou com as inovações conceituais que aconteciam no momento. Preocupavam-se com uma arte, "supostamente legitima", ao estarem, contrariamente, centrados nas técnicas, no ambiente de trabalho (no ateliê) e considerando a figura como ponto aglutinador de forças e atenção na obra. Neste contexto, a imagem, além de ser explicação do processo estético, e agrega à figura outros sentidos. Assim, os artistas optam pela produção de uma arte que, embora, inquietante, se inscreve em outro tempo, marcada por formas e conceitos sedimentados.

Os artistas que fazem opção em permanecer nesta tendência de manifestação expressiva, sustentada pelo do iderio moderno, com opção pela especificidade das linguagens (pela escultura, pintura, painel e gravura), seguem um outro percurso. Estes artistas vêem a arte com um papel social a desempenar, além do estético, mas como um instrumento de conscientização política, de denúncia e meio de socialização da obra e de questionamento. É uma arte que continua sendo realizada dentro dos ateliês.

A opção pela figura por parte destes artistas dá-se no sentido da mediação de um discurso engajado politicamente, como um instrumento de luta, a exemplo, da gravura feita pelos dos Clubes de Gravura do Rio Grande do Sul ${ }^{7}$ (1952), e a pintura praticada pelo Grupo Santa Helena ${ }^{8}$. Embora tivessem uma atuação diferenciada dos outros modernista, da época, e negassem os ditames da academia e os modismos, revelam, pela natureza do Grupo, preocupação com o social.

O período modernista, demarcado entre os anos de 1920 e 1930, prolonga-se até meados da década de 1940, em que se 
dá o seu ápice. Essa fase considerada de consolidao coincide também com a afirmação das transformações políticas, econômicas e sociais do país. É considerada de modernização social, em que perde o perfil agrário, e acontece entre as duas guerras. Em decorrência da efervescncia do momento se desenvolve a indústria, expandindo-se ao comercial e financeiro, abrindo espaços para novos acontecimentos nas décadas seguintes. Contrariamente a estes interesses - "modernos" -, a arte dos anos 60/70 vem levantar outras preocupações, diferentes das que estavam impregnadas no ideal de modernização da arte Brasileira, do começo do século XX.

Mas para os artistas de tendência moderna a preocupação central do projeto estético era à vontade de renovação da arte, associada ao desejo de construção de uma consciência atualizada da cultura nacional. (GONÇALVES, 1997).

Todavia, os artistas do Grupo Santa Helena (1930), embora contemporâneos aos modernistas agiam de modo diferente. Tinham suas raízes artísticas fincadas nas profissões artesanais; eram pintores-decoradores de residência, fotógrafos, cenógrafos ou pintores. De formação italiana, eram oriundos da pequena burguesia, em ascensão, ou advindos da classe pobre. A tendência pelo social dá-se pela origem do Grupo. Para discutir a arte, se juntavam nos encontros que realizavam após a jornada de trabalho, no Palacete Santa Helena, ao lado da Catedral da Sé, em São Paulo.

A característica principal que marca o trabalho destes artistas é o aprendizado em grupo e observação mútua, sustentada pela troca de experiências, informações, e pela pesquisa. Mas, a meta dos artistas era a liberdade de expressão, ao tentarem fugir, na época, do aprisionamento das normas da academia. Pela crença na liberdade como princípio para a expressividade não mantinham vínculos com os artistas iniciadores do movimento moderno, de São Paulo, em sua primeira fase.

Contudo, é pelas circunstâncias causadas pela Segunda Guerra Mundial; pelo isolamento das produções artísticas mundiais, falta de material e mercado, que leva os artistas a seguirem caminhos isolados, movidos pela incansável luta por uma arte legítima e autônoma. E é nesse contexto de troca de expe- 
riência e de pesquisas visuais de base italianas e de discussões por uma arte independente e criativa que DJ Oliveira, da família Capazzoli, se liga ao Grupo e com ele convive durante seis anos (de 1949 a 1955).

Inicia a carreira artística, em São Paulo, com o Grupo, centrado, assim como os demais, nos aspectos artesanais da arte. Faz incursões pelo teatro trabalhando como cenógrafo de TV, pintor decorativo de paredes e dá início às produções plásticas. Faz sua primeira exposição em 1955, com participação em uma coletiva de artistas modernos de São Paulo, no Clube dos Artistas. Naquela cidade, visita exposição de Murais de Oroszco, freqüenta a Fundação Álvares Penteado e a Associação de Arte. Convive com o grupo, e com ele, se inicia na pintura e começa a gravar em madeira.

Mas é também pelas dificuldades de sobrevivência decorrente dos acontecimentos anteriores, que se prolongam e se adentram, e pela vontade de levar as metas do Grupo em frente; de defender os ideais de liberdade e produzir uma arte independente, que DJ Oliveira se desloca, em 1956, de São Paulo e se muda para a Região centro-oeste. Para Brasília (DF), mais especificamente. Mas, pelas dificuldades da nova capital, ainda em construção, muda-se para capital de Goiás, em busca de novas possibilidades de trabalho ${ }^{9}$.

O Estado, ainda, em desenvolvimento estava à procura de novos encaminhamentos para sedimentar-se, se atualizar; e se situar no campo produtivo brasileiro. A cultura, a economia, a política, a educação e as artes eram as maiores preocupações naquele momento, mas para que mudanças acontecessem a transferência da capital para um local mais adequado à integração seria inevitável.

Enquanto a modernização artística, no Brasil, acontece no século $X X$, com o modernismo, com a preocupação de um projeto poético voltado para a renovação da arte, agregada à construção de um pensamento atualizado sobre a cultura, deflagrado em 1922, com a Semana de Arte Moderna, em Goiás, e nas artes plásticas, isto só acontece mais tarde. Os ideais que dão início à arte moderna começam a se instalar e desenvolver três décadas depois, com a nova capital, embora o pensamento 
modernista já se fizesse presente no meio literário goiano ${ }^{10}$.

Em Goiás, ao contrário dos demais estados do Brasil que já se destacavam do ponto de vista dos acontecimentos artisticamente modernos, como Rio de Janeiro e Rio Grande do Sul e São Paulo, os ideais do modernismo chegam bem mais tarde, em 1954, associado à transferência da antiga capital - da Cidade de Goiás, com sua historia vinculada ao ouro, para Goiânia.

O movimento de transferência da capital deu-se, efervescente, com o propósito de inserir Goiás no panorama econômico e cultural, mas a partir de uma nova forma de organização social, centrada no urbano. Por Goiânia estar situada num local geograficamente bem situado, com acesso facilitado ao restante do país, pelas estradas de ferro, esperava-se um entrosamento mais adequado de Goiás com os demais estados. Sem dúvida, não se pode esquecer de um outro acontecimento, importante, próximo a Goiânia, que é a fundação da capital do Brasil. A nova capital do país despertava, de certa forma, uma corrida para o Centro-Oeste.

Na região goiana a origem e o incremento das artes plásticas, e, conseqüentemente, da cultura urbana; artes plásticas, teatro, música e dança acontecem, simultaneamente, a partir dos avanços sócio-econômico de Goiás e da capital, associados à decadência do ouro o que implicou, nos anos trinta (1937), na transferência da capital da cidade de Goiás para Goiânia. Com a mudança da cidade para um local mais acessível. Com isso, os interesses do estado se deslocam em duas direções: para o urbano, mas sem perder de vista o rural, pois é onde se concentra a maior parte da economia do estado.

A falta do ouro leva ao despregamento da sociedade, do campo para a cidade, e, conseqüentemente, novas necessidades são criadas, como a exemplo, do ensino superior, responsável pela implementação e desenvolvimentos das artes, na região. É, neste contexto, efervescente e de necessidade de novos diálogos com o restante do país: da integração de da nova capital Goiás ao cenário nacional, e da criação de Brasília, cidade próxima à Goiânia, que Oliveira se muda para Goiás, em buscas de novas perspectivas de trabalho. 
Mas é também, a partir da inserção do artista, no local, que ele se insere em outras narrativas: nas histórias, nos causos ${ }^{11} \mathrm{e}$ na cultura do lugar, as quais vão servir como suporte e pretexto, como motivação e desencadeadores do seu processo construtivo, plástico.

Em Goiânia, DJ Oliveira retoma o seu trabalho como pintor e como cenógrafo, no Teatro de Emergência, compondo o Grupo de João Bennio. Posteriormente, funda o primeiro ateliê de pintura da cidade e se insere na carreira acadêmica, ensinando pintura e gravura.

\section{Procedimentos de criação de gravura}

DJ Oliveira se muda de um lugar para outro, e em princípio parece ficar sem lugar, mas ao contrário da simples acomodação ou assimilações passivas da cultura tenta encontrar a sua maneira de pertencer ao novo ambiente pela produção da obra. Para isto, apropria-se das narrativas da cultura universal e as materializa, pelo grafismo, através de desenhos amplos e detalhados. Também se apropria da matéria do ambiente sociocultural no qual está inserido (das historias, dos causos do lugar) como pretexto para a criação, mas a sua maneira. Para isto, para produzir a obra, adota procedimentos distintos: Faz, pelo grafismo, narrativas denominadas de traduo para selecionar delas os aspectos plásticos, para produzir a obra.

Para se expressar e comunicar, pela arte, o artista faz apropriação e transformação da realidade. DJ Oliveira apropria das histórias da cultura universal e do lugar com propósito estético, e de inserção no ambiente. Pelo modo de construção plástico podemos compreender como lida com a matéria. Isto significa que devemos olhar para os documentos de processo de criação para entender formas de diálogos.

As histórias são o ponto de sustentação, matéria prima para construir a obra. Para isto, as transforma e as adapta a seu modo. Ao iniciar a materialização da idéia sobre o papel formula hipteses plsticas, ou seja, testa, graficamente, diferentes maneiras de representar uma mesma figura(s) no espaço do 
papel, ao procurar o modo mais adequado. Cria, inicialmente, um personagem (Cristo: Figura 1). Na cena seguinte, vê-se o número de personagens ser aumentada no desenho. (Figura 2). Muda a figura de Cristo de posição no espaço do papel (Figuras 1, 2, 3 e 4) e acrescentas outras figuras. Faz, pelo grafismo, narrativas de tradução, amplas, (figura 5) e delas retira apenas o necessário à sua maneira de representação, plástica (Figura B). A figura B, resultante do corte, denomina-se narrativa de mediao. Dela origina-se a obra.

Contudo, os procedimentos, de apropriação e filtragem, se diferenciam no processo de criação, não pela função comunicativa que a obra terá, ou pelos métodos e técnicas a serem utilizados, tampouco pela natureza da linguagem - se pintura, mural ou gravura -, o artista leva em conta a origem das histórias; se pertencem à cultura universal, a exemplo de obras produzidas a partir da Divina Comédia, ou se do lugar (se decorrente de assuntos da cultura local).

O uso de procedimentos de seleção e/ou filtragem está as-

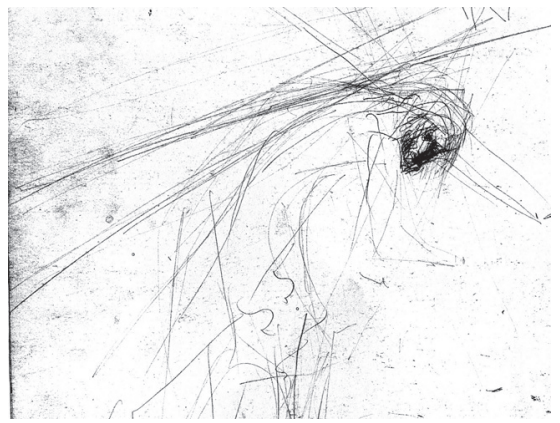

Figura 1

Título: VIII Estação (Croqui I)

Data: 1980

Técnica: Desenho sobre papel canson Água-tinta, água-forte e água-tinta de açúcar sobre chapa de ferro Dimensões: $30 \mathrm{~cm}$ x $40 \mathrm{~cm}$ Proprietário: Família Oliveira Assinatura: (Não conta)

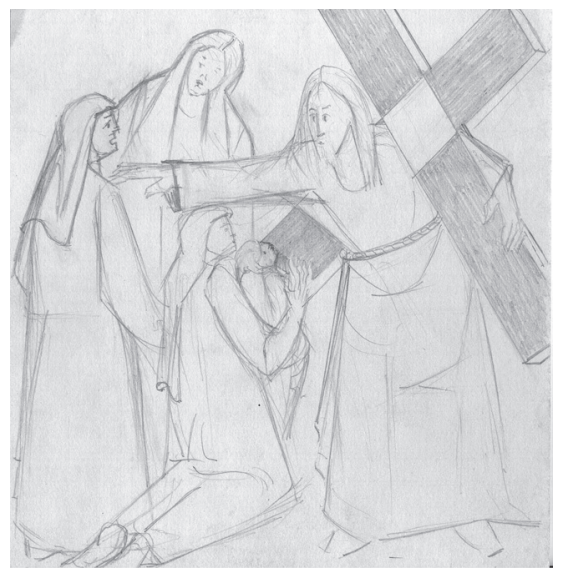

Figura 2

Título: VIII Estação (esboço I)

Data: 1980

Técnica: Desenho sobre papel canson Água-tinta, água-forte e água-tinta de açúcar sobre chapa de ferro Dimensões: $30 \mathrm{~cm} \times 40 \mathrm{~cm}$ Proprietário: Família Oliveira 
sociado ao modo de criação dele; se o desenho decorre de interpretação de outras obras, a exemplo de Via Sacra (Figura 6) e Don Quixote da La Mancha, ou se a obra decorre de criação livre; sem modelo ou referência - (Figuras 9 e 10). Ao recorrer às narrativas da cultura; universal ou do lugar para criar a obra, DJ Oliveira utiliza diferentes procedimentos para filtrar a matéria. Cria as narrativas de tradução e faz adaptações, ou seja, seleciona das narrativas de tradução, primeira versão dos fatos, apenas o que convém ser destacado em sua obra, em função da expressividade e do recado que quer passar.

Para realizar a operação; para fazer o aproveitamento das narrativas da cultural universal (Don Quixote, Divina Comédia e Via Sacra) DJ Oliveira procede de uma maneira e para filtrar informações nas narrativas decorrentes da cultura do lugar, recorre a um outro tipo de procedimentos para filtragem da matéria. A operação é realizada apenas por incluso e/ou excluso,
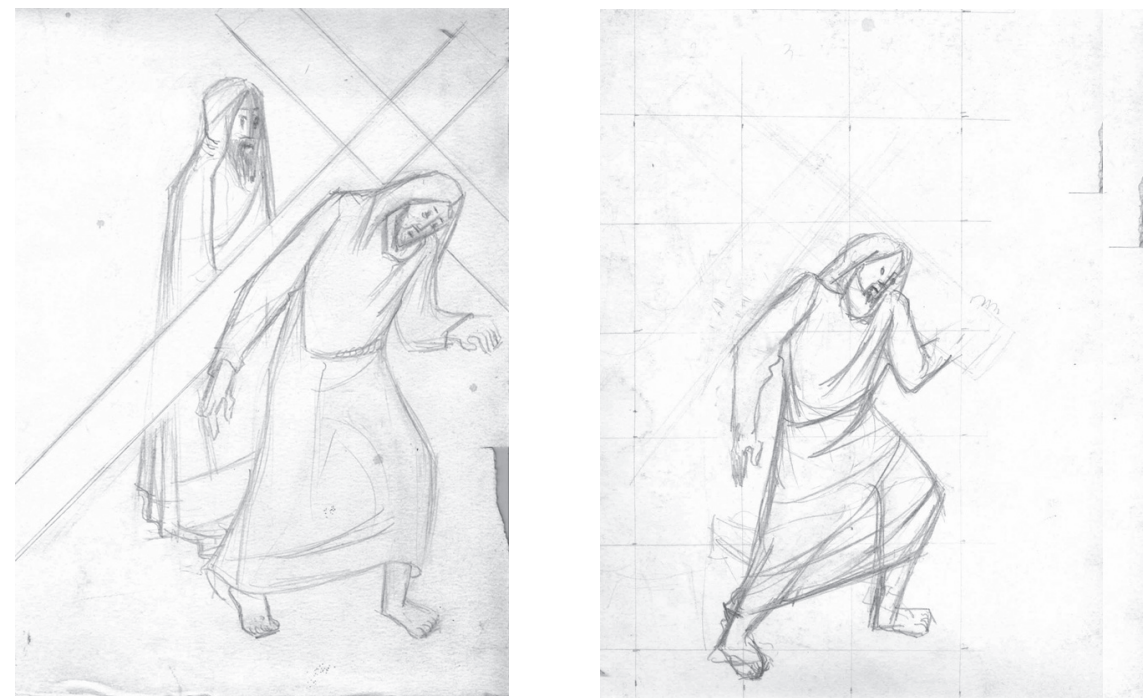

Figuras 3 e 4

Título: VIII Estação (croqui II e croqui III)

Data: 1980

Técnica: Desenho sobre papel canson

Água-tinta, água-forte e água-tinta de açúcar sobre chapa de ferro 
Figura 5

Título: VIII Estação (esboço II)

Data: 1980

Técnica: Desenho sobre papel

canson

Água-tinta, água-forte e água-tinta de açúcar sobre chapa de ferro

Dimensões: $30 \mathrm{~cm} \times 40 \mathrm{~cm}$ Proprietário: Família Oliveira

Assinatura: (Não conta)

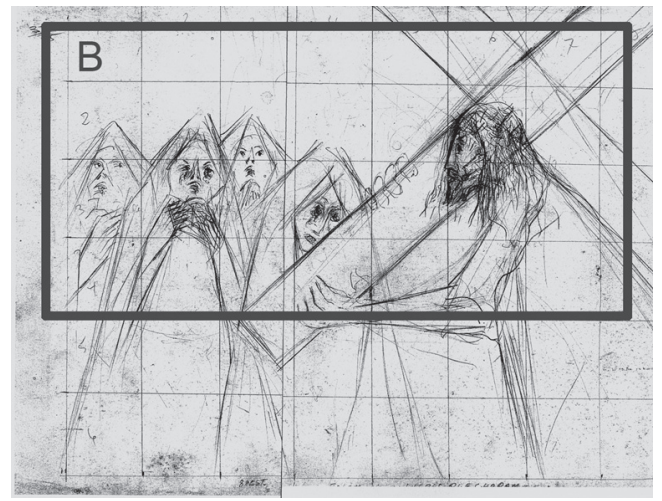

ou seja, ao invés de filtrar pela aplicação de cortes, simplesmente retira da narrativa de tradução, primeira versão gráfica, dados não convenientes ao seu modo de representação. A esse procedimento denomina-se adaptao simultnea.

Para criar a partir de narrativas da cultura do lugar DJ Oliveira faz pelo grafismo narrativas de tradução e, sobre elas, são aplicados janelas de corte, ou o close, recurso que traz de sua experiência com a fotografia, vivida no cinema e no teatro. Pelo recurso, retira das narrativas de tradução pontos de tenso, denominados, por nós de sntese plstica. Esses pontos são transformados em obras.

Ao reconfigurar os cenários (produzir os esboços) e transformá-los em obras - ao ilustrar as narrativas da cultura universal (Figura 6) DJ Oliveira dá ao conteúdo outras configurações; recria personagens e espaço representacional (Figuras 1, 2, 3, 4, 5 e 7). Dá aos cenários novas interpretações gráficas (Figura 7). Reconfigura, compositivamente as narrativas, adaptando-os à sua maneira, necessidade plástica e comunicativa.

O recurso de close (janela de corte) ou procedimento de filtragem da matéria, por sua vez, e nas narrativas de tradução, primeira forma de materialização gráfica de uma idéia, é utilizado com objetivos distintos; a) para excluir; b) fazer aproximações e ou b) para ressaltar na narrativa de mediao detalhes e 
valorizar na obra.

Recorta para selecionar nas narrativas - de tradução ou mediação - apenas o necessário para passar o seu recado e concepções estéticas. A sntese - imagem resultante do corte - tanto pode ser transformada em pintura, painel, quanto em gravura. A intenção de aplicar os recursos de filtragem ou de testagem de hipóteses plásticas tem a função de experimentar ou retirar da narrativa de tradução, transformada em composio o que denominamos de sntese plstica, ou ponto de tensão, como mostra a figura 5, ou encontrar a forma "perfeita" para a

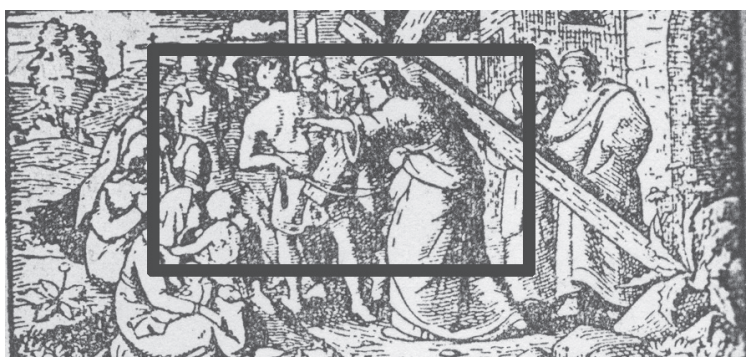

Figura 6

(Obra referência). VIII Estação: Jesus fala às mulheres que choram llustração de um Manual de orações e exercícios piedosos, um dos manuais mais usados durante as primeiras quatro décadas do século XX. Foi publicado pelos devotos de Nossa Senhora do Perpétuo Socorro, em 1944. É enriquecido de orações quotidianas, exercícios e orações a Jesus, a São José e a diversos santos.

Figura 7

Título: VIII Estação: Jesus

fala às mulheres que choram (esboço II) Autor: DJ Oliveira Data: 1980

Técnica: Água-tinta, águaforte e água-tinta de açúcar sobre chapa de ferro

Dimensões: $30 \mathrm{~cm} \times 40 \mathrm{~cm}$ Proprietário: Família Oliveira Assinatura: (Não conta)

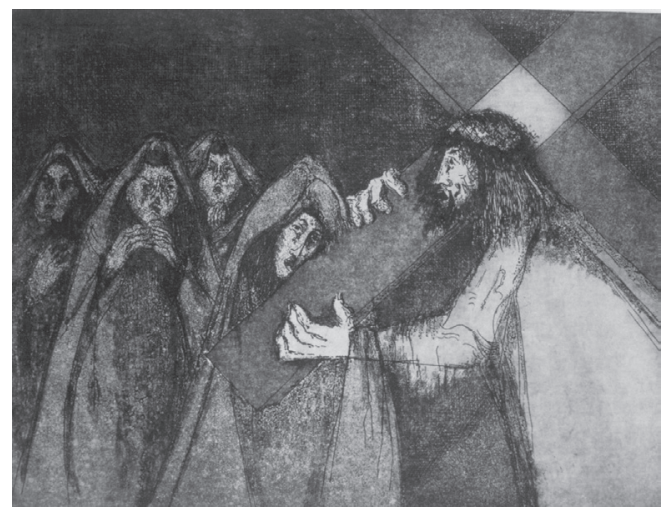


representação da cena.

Ao materializar as idéias em narrativas de tradução, transformá-las em narrativas de mediação e em linguagens: - pintura, mural ou gravura, dá nomes às obras para indicar o assunto tratado, a exemplo de Via Sacra, um dos temas explorados pelo artista, na técnica da xilografia e calcografia. As séries de obras, por sua vez, são subdivididas em ttulos, a exemplo da $X V$ Estao. As obras dão origem a uma série de gravuras ou Ibum (conjunto de obra). As obras recebem número, fracionário, para controle, ético, do artista, sendo o numerador o indicador da ordem de tiragem e o denominador o número de cópias.

A função do texto escrito nas obras - dos ttulos - é para identificar as obras dentro de uma temática ou para dar informações. Os títulos podem remeter o espectador aos tempos históricos e de produção, aos espaços, aos lugares, aos personagens, às situações e acontecimentos. O desenho evidencia-se, no processo construtivo do artista, como ação intermediária. A sua função é dar sustentação física ao pensamento visual. Para dar fisicalidade à idéia. Pelo desenho DJ Oliveira torna suas idéias evidentes. Pelo desenho faz a mediação entre as narrativas colhidas na cultura e as plásticas, nas linguagens da gravura, da pintura e do mural. Os desenhos evidenciam-se no processo de criação de DJ Oliveira de duas formas: em esboos e croquis.

Em DJ Oliveira o desenho não é linguagem final e tem função intermediária ao se posicionar entre idéia, matéria e obra. É base para a construção da obra.

Todavia, a obra impressa e, em mural, resulta dos esboos. Para essas duas formas de linguagens o desenho age como pr-obras, ao serem tecnicamente mais elaborados (detalhados). Os desenhos dão indicações da obra futura. Não são croquis, como os destinados à pintura e a xilografia. Nesses processos, as representações gráficas são fugazes, indefinidos. A função do croqui indica assegurar pensamentos fugidios, passageiros, enquanto os esboços agem como indicadores de obra. Mas ambos - esboços e croquis - são referencia para os passos a serem seguidos pelo artista na execução da obra. Tem função de 
orientá-lo: de comunicação intapessoal, mas, ao serem vistos pelo espectador tem função de tirar o processo de construção de sua condição de autoconfidencial.

O papel dos documentos de processo e, no projeto do artista, além de linguagem intermediária, é servir de banco de dados, não no sentido de memórias que ficam armazenadas, depositadas no passado, mas vivas, que podem pinçadas em seus arquivos e retomadas pelo artista a qualquer momento, sendo atualizadas, ressemantizadas nas três linguagens.

A função dos materiais assim como do desenho é dar sustentação ao processo do artista para a produção da obra e são vistos apenas pela obra. Pelos modos de ação: de desenhar e gravar procura-se verificar como a construção da obra acontece. Por ser pintor, muralista e gravador e fazer desenhos para as três linguagens favorece ao transito dos signos pelas linguagens, pelas obras e pelo projeto poético. Um mesmo personagem pode ser visto em gravura, mural e pintura.

Pelo modo como lida com os objetos colhidos na cultura, e pela maneira como esses são levados para os documentos - para os desenhos - podemos verificar formas de diálogo que estabelece com eles. Torna-se possível conectar informações à rede em que se dá a criação. Podem-se compreender entrelaçamentos que envolvem a criação, e descobrir os diferentes níveis de pensamentos em que se dá a produção criadora.

Para fazer a obra o artista arquiteta uma cadeia de procedimentos; escreve pelo desenho e sobre diferentes tipos e formatos de papeis diferentes figuras humanas. Apresenta diferentes formas de concepções de espaço plástico, denominados de cenários visuais. Neles inscreve figuras e produz ambientes para a atuação deles. A criação de cenrios dá-se em busca da expressividade e da comunicação da futura obra com o público. As personagens agem nas narrativas visuais do artista não como figuras ilustrativas apenas, mas como interlocutores da mensagem do artista. Tem a função de levar o seu recado ao espectador. Mas embora pareçam independentes estão presas as Histórias criadas pelo artista

DJ Oliveira vivencia diferentes fases de exploração da figura. As diferentes hipóteses plásticas revelam-se como exercícios 


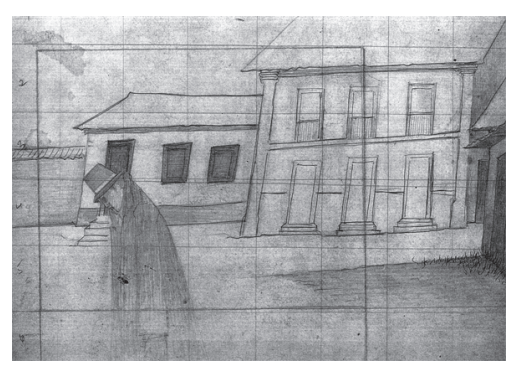

Figura 8

Título: (Esboço) O Tormento do Juiz Data: 1977

Técnica: Desenho sobre papel cançon Dimensões: $1,22 \mathrm{~cm} \times 0,93 \mathrm{~cm}$ Proprietário: Família Oliveira Assinatura. (Não conta)

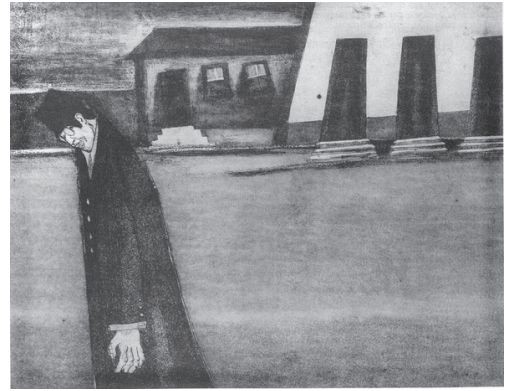

Figura 9

Título: Data: 1976

Técnica: Água-tinta, água-forte e água-tinta de açúcar sobre chapa de ferro

Dimensões: $35 \mathrm{~cm} \times 45 \mathrm{~cm}$

Proprietário: Família Oliveira Assinatura: pelo artista DJ Oliveira
Figura 10

Título: O Tormento do Juiz

Data: 1977

Técnica: Têmpera sobre madeira

Dimensões: $1,22 \mathrm{~cm} \times 0,93 \mathrm{~cm}$

Proprietário: Edna Goya

Assinatura. c.i.d. (pelo artista

D.J. Oliveira)

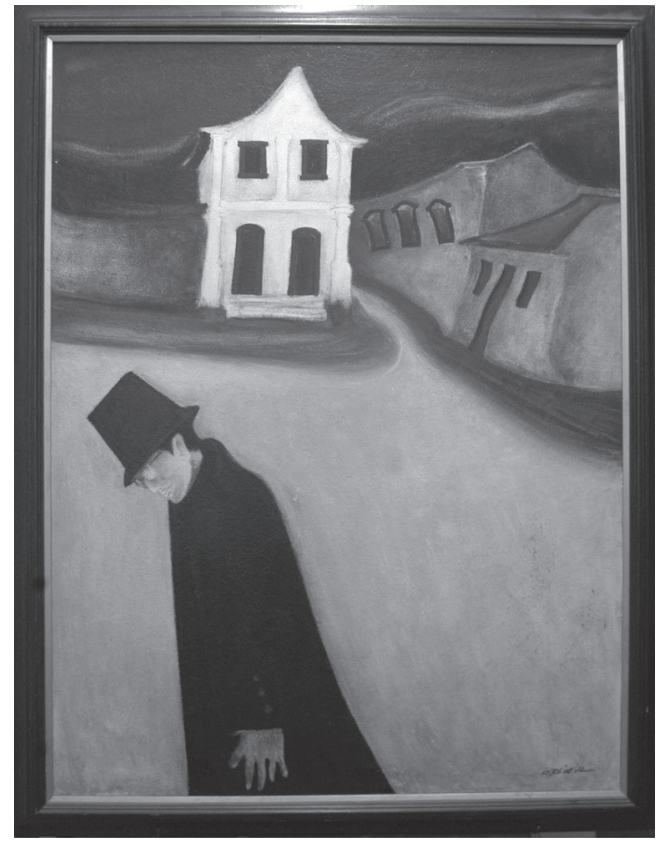


em busca da melhor maneira de se expressar. Denunciam fases de aprender, observar; armazenar experiências, e de codificar a matéria em desenhos e de uso de materiais. Revela diferentes de modos de construção do espaço ao aplicar a perspectiva e bidimensional. Neste modo de composição a figura é situada no espaço do papel a partir de uma linha, denominada de referncia. Em torno da figura principal se desenvolvem as demais personagens.

Na tentativa de encontrar a forma "perfeita" para sua expressividade experimenta diferentes estilos. Experimenta diferentes tendências de representação gráfica da figura humana, ou seja, testa figura pelo naturalismo; impressionismo; cubismo; surrealismo e expressionismo reduzido (com deformação de pés e mãos) e expandido (com deformação expandida para todo o corpo).

Para expressar-se, no entanto, o artista move-se conduzido por razões internas e externas, mas o seu intuito indica ser a comunicação, que acontece de duas maneiras diferentes: intapessoal: dele consigo mesmo e pela obra. Inicialmente a comunicação acontece de modo subjetivo, ao orientar-se pelos esboos e croquis no seu processo produtivo. Através dos documentos de criação estabelece diferentes diálogos; consigo, com a cultura, e com conhecimentos acumulados, historicamente, e ao tirar os documentos de sua condição autoconfidencial. Mas também se comunica de forma interpessoal, externamente, pela obra, ao colocá-la em contato com o público.

Podemos dizer que os documentos de processo de criação se evidenciam como necessidade para dar forma ao pensamento visual. São materializadas graficamente pelo desenho, em forma de esboços e croquis, e transformados em obra. Concretizam-se materialmente, como inteno de obra, necessitando, portanto de causação física final - de métodos e técnicas e materiais.

A criação se manifesta, no processo, como algo que se desencadeia, em diferentes níveis de pensamento e etapas, ou seja, acontece processualmente, se consolidando em diferentes formas de experimentação e, a partir de necessidades do artista de se expressar e comunicar. 
O processo de materialização da obra dá-se a partir de apropriações, Histórias do lugar, tomadas pelo artista como motivação para a produção. As narrativas servem como desencadeadoras da criação. O artista produz a sua arte a partir das Historiais do lugar (dos causos). Constituem-se como ponto de sustentao para a criação plástica. Apropria-se das Historiais, mas as adapta plasticamente à sua maneira e necessidade. Produz narrativas de tradução ao codificar a matéria em desenhos, pelo grafismo, para dar formato as idéias.

DJ Oliveira testa diferentes formas de representação da figura para registrar o que capta no ambiente cultural. Faz narrativas visuais denominadas de traduo para mediar a matéria (Histórias ou causos). As transforma em visualidade pelo desenho para evidenciar o que foi observado e selecionado. Com elas, produz o plástico, ao apresentá-las, criativa e artisticamente, via força da expressão criadora, por meio da linguagem de murais, pinturas ou gravuras, de acordo com suas concepções; estética e ética; meta a ser atingida.

O olhar do artista capta a matéria (as Histórias) na cultura, universal e do lugar. Nelas, faz cortes para retirar apenas o essencial; para captar o ponto de tenso, necessário às construções plásticas. Busca recuperar, pelo uso do "real", transformado em plástico (fictício), o particular e poético. Recorre a imagens da vida cotidiana e de textos literários. Explora figuras de mulher, homens de poder, trabalhadores, figuras da sociedade, do cotidiano e da fé cristã. Recorre aos costumes, regionais, assim como a outros objetos da cultura. Não que o seu propósito seja retratar ou ilustrar a realidade goiana, mas como pretexto para sua criação. Através de sua arte estabelece com o meio novos diálogos.

Ao se apropriar de matéria da cultura do lugar DJ Oliveira não se restringe apenas a signos da realidade, social, local. São signos que refletem, nas imagens, diferentes realidades; nacional e universal. Ao trazer Don Quixote para os trilhos da ferrovia goiana reionaliza o universal, mas, ao mesmo tempo, universaliza o regional. Apropriam-se do personagem para recontar, pelo visual, outras narrativas. A obra decorre da comunicao que o artista estabelece com o meio cultural e, a imagem, da 
dinâmica da ao do signo. Decorre da semiose, movimento do signo durante a criação. Entende-se que a comunicação, associada à criação, se dá de modo intrapessoal e se revela pelas trocas que o artista realiza com o seu contexto sociocultural: histórico, artístico, técnico, material e memória acumulada. (SALLES, 1998).

Durante a realização da obra estabelecem-se diferentes formas de diálogos, internos: do artista consigo próprio; com a obra que está em processo de construção; com o meio sociocultural. Tais diálogos se dão pela apropriação que o artista faz, como agente que recolhe e filtra pelo seu olhar a matéria no seu espaço vivencial para a elaboração de sua obra. Compreende-se $\mathrm{o}$ ato criador como resultado de uma mente em ação, que faz vários tipos de reflexões (SALLES, 2002). A obra resulta de entrelaçamentos das ações e das relações estabelecidas ente produtor e mundo. Resulta do conhecimento, experiência, materiais, métodos, técnicas, da coleta que o artista faz no ambiente sociocultural e dos procedimentos que elabora para resolver os problemas da criação. É claro que a sensibilidade não pode ser desconsiderada nesse processo.

Para coletar a matéria o artista se coloca frente ao ambiente como uma espécie de torre de observao, sensvel, que olha, seleciona pela percepção, recorta e leva para a obra apenas a matéria que lhes convém, transformada à sua maneira, produtiva e sensível.

O que difere as obras de DJ Oliveira decorrentes das narrativas tomadas da cultura universal (Don Quixote) das narrativas originárias da cultura do lugar se refere ao modo como faz uso da matéria. A diferença é denunciada pelo modo de materialização plástica das histórias. Diz respeito ao modo, singular, de fazer uso da matéria tomada pelo artista e, ao momento histórico, em que os fatos acontecem e o sensibilizam. Refere-se ainda, ao modo como as Historias visuais são narradas pelo artista, crivadas pelas impregnações de seu olhar. A criação decorrente da literatura, universal, denomina-se criação por referncia ou modelo (Figura 6).

No modo de leitura em que se tem como objeto as ações do artista leva-se em consideração o momento em que a "rea- 
lidade" foi percebida, captada, filtrada e representada poeticamente, isto é, não se pode perder de vista o contexto externo, as técnicas, as linguagens e forma de abordagem da figura e do drama humano vivido pelo artista. A preocupação do artista tende a transformar realidades em ficção, mas impregnada de seus sentimentos.

DJ Oliveira nos revela temas do cotidiano do lugar, diversificados, a exemplo A Estrada de ferro, Famlia, Conspiradores, A Fiandeira e assuntos líricos, a exemplo de Arlequins. Através deles discute condição social, valores, costumes, diversão e política. Os temas retratados em suas obras indicam não somente situações do homem ou da cultura goiano, de meados do século XX, ou de moradores da cidade de Goiás, sociedade descendente da aristocracia conservadora, mas sujeitos que podem ser encontrados ou reconhecidos em qualquer outro lugar.

Pelos documentos e obras o artista se constata o seu modo peculiar de olhar a realidade. Ao mesmo tempo em que elege um tema para criação se utiliza dele pra tecer criticas, ou ironizar ainda que plasticamente, pois é esta a sua forma de questionar, de ler e de dar a sua contribuição ao mundo. A figura do Juiz é denunciada, na gravura e na pintura, de forma irônica. O juiz parece derrotado, com mãos grandes e ombros caídos, deprimido. (Figuras 9 e 10). Pela forma da mão da figuração, exagerada, e corpo depressivo, dá pistas de suas inquietações e críticas, mas, ao mesmo tempo, a deformação exagerada denuncia servir de atrativo para chamar a atenção do espectador. Parece denunciar o poder, pois a obra é realizada, em 1967, período de repressão militar. DJ Oliveira sofre inúmeras perseguições nessa época. Porém, muitas criações plásticas, nos esboços e obras, não se encontram, necessariamente, inseridas num contexto social ou político, mas apenas no plano plástico. 


\section{Notas}

1. Em São Paulo, o surgimento de grupos de artistas decorre da necessidade de custear - local de reunião e materiais artísticos, mas, especialmente, os modelos que posavam para os artistas. Os Núcleos funcionavam como uma espécie de escritório onde os artistas eram procurados para prestar serviços de decoração. Representavam os decoradores atuais. Na verdade, os artistas desses grupos originavam-se dos bairros da periferia paulista e, por esta razão, eram considerados sem status social para pertencer aos demais grupos de arte que, juntos, haviam liderado a Semana de Arte Moderna (DJ OLIVEIRA, 2005). Os artesãos juntam-se no edifício Santa Helena para desenhar e discutir arte, onde se localizava a sede da Federação Brasileira de Sindicatos dos Trabalhadores. O local era uma espécie de escritório de prestação de serviços. O grupo agia de forma independente. A razão do afastamento dos artistas do GHS de toda espécie de polêmica, estética, ou de "modernos" e "acadêmicos", da concentração em torno das questões do métier, do ofício, da tendência para o artesanal, decorria da origem dos artistas: de serem artesãos, de serem estrangeiros, devido às perseguições fascistas, que imprimiam o terror nazista no país. Além das atividades artesanais, desenhavam, pintavam, trocavam idéias sobre os progressos que faziam nas "belas pinturas". Eram todos oficiais em vista de passar a mestres de obras. (Conferir PEDROSA, Mário. Mundo homem, arte e crise. São Paulo: Perspectiva, 1975).

2. EGBA - primeira escola de artes de Goiás criada pela Universidade de Goiás, atual Universidade Católica de Goiás, em 1952. Começou a funcionar no segundo semestre de 1953, com a primeira turma de preparação para o vestibular de 1954.

3. Desse grupo de artistas participaram os pintores Juca de Lima, Agostino de Souza, Siron Franco, Roosevelt, Washington Honorato e Amaury Menezes. Depois, Isa Costa, Ana Maria Pacheco, Vanda Pinheiro e outros.

4. Método composto pelas técnicas de gravação ao fio e de topo.

5. Processo composto pelas técnicas: a) seca ou a traço, a buril, a ponta-seca e maneira-negra e b) em água-forte ou em meio tom - água-tinta, maneira-negra, pontilhado, água-tinta de açúcar, verniz mole, maneira-negra de pastel e a punção.

6. Termo utilizado pelos artistas considerados "tradicionais", especialmente na década de 1960, para indicar o domínio técnico como requinte da gravura. Os artistas defendiam a idéia de que o gravador deveria ser responsável por todo o processo de elaboração da obra, inclusive pela impressão.

7. Fundado em Porto Alegre, no começo da década de 1950, com o nome "Clube dos amigos da gravura" o primeiro clube era composto de cinco gravadores: Carlos Scliar e Vasco Prado seus fundadores, Danúbio Gonçalves, Glênio Bianchetti e Glauco Rodrigues.

8. Desse grupo participavam artistas atuantes e engajados politicamente como: Alfredo Rizzoti, Alfredo Volpi, Fúlvio Pennacchi, Clóvis Graciano, Manoel Martins, Alfredo Rullo Rizzotti, Humberto Rosa e posteriormente Rebolo, Mário Zanini, artistas que assimilaram lições de Van Gog, dos impressionistas a exemplo de Matisse, do expressionismo, do realismo. Muitos destes artistas estiveram em Goiânia, em 1954, na abertura do I Congresso Brasileiro de Intelectuais, na inauguração da Escola Goiana de Belas Artes (EGBA).

9. É certo que a possibilidade de recomeçar a carreira artística em um ambiente novo motivam o artista a sair de São Paulo, mas DJ Oliveira confessa, nos bastidores (Entrevista, DJ Oliveira, 2005), que um outro motivo o havia trazido para Goiás; uma grande paixão pela mulher com quem se casa, tem três filhos e vive até a sua morte.

10. Em 1942, surge o primeiro movimento cultural de Goiânia com o Grupo Oeste (19421945), formado por intelectuais de diferentes tendências, atuantes no campo literário. Criaram-se, nesta época, institutos e entidades de fins culturais, faculdades, unidades 
atualmente inseridas nos complexos universitários de Goiânia - Universidade Católica de Goiás (UCG) e Universidade Federal de Goiás (UFG).

11. Termo adotado pelo humor caipira, manifestação fortemente presente nos programas culturais da cidade e que como figurantes os Contadores de Causos.

\section{Referências Bibliográficas}

FOCILLON, H. Vida das formas. Rio de Janeiro: Zahar Editores (p. 73).

GONÇALVES, Lisbeth Rebollo. Prefácio. In: ALVARADO, Daisy V. M. Peccinini de (Coord.). Arte Brasileira: 50 anos de História no Acervo do MAC USP. Fundo Nacional da Cultura, Ministério da Cultura, Governo do Estado de São Paulo, Secretaria da Cultura, departamento de Museus e Arquivos, 1997. p. 9-15.

GOYA, Edna de Jesus/ A Arte da Gravura em Gois/Edna de Jesus Goya. Dissertação (Mestrado em Ciência da Comunicação), 1998, 187 p.

SALLES, Cecília. Gesto inacabado: processo de criação artístico. São Paulo: FAPESP /Anna Blumme, 1998.

Crítica genética e semiótica: uma interface possível. In: ZULAR, Paulo. (Org.). Criao em processo. São Paulo: NAPG/USP, 2002. p. 177-201

OLIVEIRA, D. J. Gravura em ferro. Goiânia, 2005. Uma fita cassete (20 min.) color PAL-M, VHS. (Gravura. Entrevista concedida a Professora Edna de Jesus Goya).

VERNASCHI, Elvira. Novas pesquisas, novos conceitos. Arte Brasileira: 50 anos de História no Acervo do MAC USP. Fundo Nacional da Cultura. Ministério da Cultura. Governo do Estado de São Paulo: Secretaria da Cultu-

\section{EDNA GOYA}

é professora Adjunta da Faculdade de Artes Visuais/UFG - GO, Doutora em Comunicação e Semiótica pela Pontifícia Universidade Católica de São Paulo/SP; Mestre em Arte Publicitária e Produção Simbólica pela ECA/USPSP (1998); Curso de Especialização em Educação (UCG, 1986) e em ArteEducação (UFG, 1989); Bacharel em Artes Visuais-Gravura (UFG, 1992) e Licenciatura em Desenho e Plástica (UFG, 1983), Coordenadora do Curso de Artes Visuais - Licenciatura, da Faculdade de Artes Visuais da Universidade Federal de Goiás, Membro do Centro de Estudos em Crítica Genética da PUC/SP; Membro do Comitê Interno do Programa de educação tutorial (PET/UFG). 